\title{
Juvenile granulosa cell tumour of the ovary presenting with hyperprolactinaemic amenorrhoea and galactorrhoea
}

\author{
Ahmed Iqbal*, Peter Novodvorsky*, Alexandra Lubina-Solomon, Fiona M Kew ${ }^{1}$ \\ and Jonathan Webster \\ Department of Diabetes and Endocrinology, Northern General Hospital, Sheffield Teaching Hospitals NHS \\ Foundation Trust, Herries Road, Sheffield S5 7AU, UK \\ ${ }^{1}$ Department of Gynaecological Oncology, Royal Hallamshire Hospital, Sheffield Teaching Hospitals \\ NHS Foundation Trust, Glossop Road, Sheffield S10 2JF, UK \\ *(A lqbal and P Novodvorsky has joint first authorship)
}

\author{
Correspondence \\ should be addressed \\ to P Novodvorsky \\ Email \\ p.novodvorsky@ \\ sheffield.ac.uk
}

\section{Summary}

Secondary amenorrhoea and galactorrhoea represent a common endocrine presentation. We report a case of an oestrogenproducing juvenile granulosa cell tumour (JGCT) of the ovary in a 16-year-old post-pubertal woman with hyperprolactinaemia amenorrhoea and galactorrhoea which resolved following surgical resection of the tumour. This patient presented with a 9-month history of secondary amenorrhoea and a 2-month history of galactorrhoea. Elevated serum prolactin at $7081 \mathrm{mIU} / \mathrm{l}$ and suppressed gonadotropins ( $\mathrm{LH}<0.1 \mathrm{U} / \mathrm{l} ; \mathrm{FSH}<0.1 \mathrm{U} / \mathrm{l}$ ) were detected. Serum oestradiol was significantly elevated at $7442 \mathrm{pmol} / /$ with undetectable $\beta$-human chorionic gonadotropin. MRI showed a bulky pituitary with no visible adenoma. MRI of the abdomen showed a $4.8 \mathrm{~cm}$ mass arising from the right ovary with no evidence of metastatic disease. Serum inhibin B was elevated at $2735 \mathrm{ng} / \mathrm{l}$. A right salpingo-oophorectomy was performed, and histology confirmed the diagnosis of a JGCT, stage International Federation of Gynaecology and Obstetrics 1A. Immunohistochemical staining for prolactin was negative. Post-operatively, oestrogen and prolactin levels were normalised, and she subsequently had a successful pregnancy. In summary, we present a case of an oestrogen-secreting JGCT with hyperprolactinaemia manifesting clinically with galactorrhoea and secondary amenorrhoea. We postulate that observed hyperprolactinaemia was caused by oestrogenic stimulation of pituitary lactotroph cells, a biochemical state analogous to pregnancy. To the best of our knowledge, this is the first report of hyperprolactinaemia as a result of excessive oestrogen production in the context of a JGCT.

\section{Learning points:}

- Hyperprolactinaemia with bilateral galactorrhoea and secondary amenorrhoea has a wide differential diagnosis and is not always caused by a prolactin secreting pituitary adenoma.

- Significantly elevated serum oestradiol levels in the range seen in this case, in the absence of pregnancy, are indicative of an oestrogen-secreting tumour.

- JGCTs are rare hormonally active ovarian neoplasms mostly secreting steroid hormones.

- Serum inhibin can be used as a granulosa cell-specific tumour marker.

- JGCTs have an excellent prognosis in the early stages of the disease. 


\section{Background}

Hyperprolactinaemia constitutes a common endocrine presentation. The commonest causes of symptomatic nonphysiological hyperprolactinaemia are prolactinomas, other pituitary and parasellar tumours, medication use, renal failure and hypothyroidism. Clinically, hyperprolactinaemia typically presents with galactorrhoea, hypogonadism and infertility (1). Treatment depends on the underlying aetiology and may simply involve withdrawal of the causative agent or treatment of the causative endocrine condition. In the case of pituitary or parapituitary lesions, treatment may include a dopamine agonist therapy, surgery or radiotherapy (1).

Ovarian granulosa cell tumours are rare hormonally active neoplasms accounting for $\sim 3-5 \%$ of all ovarian cancers (2). Juvenile granulosa cell tumours (JGCTs) of the ovary are considered to be more aggressive than the adult type but also far less common, representing only $5 \%$ of all granulosa cell tumours in the paediatric age group (3) (4). Granulosa cell tumours secrete steroid hormones - mostly oestrogens and less commonly androgens and progestins (2), but secretion of prolactin (5) and insulin (6) has been described. Most granulosa cell tumours secrete inhibin which has been used as granulosa cell-specific tumour marker (7). Tumour staging uses the International Federation of Gynaecology and Obstetrics (FIGO) system. Most JGCTs are FIGO stage 1 at the time of diagnosis and have excellent cure rates (5-year survival rate 90-95\%) with surgery being the mainstay of therapy. Advanced stages bear a worse prognosis (5-year survival rate $25-50 \%$ ) and require adjuvant chemotherapy with cisplatin-based regimens (8).

\section{Case presentation}

A 16-year-old Eastern European Romani woman (nulligravida and nullipara) presented with a 9-month history of secondary amenorrhoea and a 2-month history of bilateral galactorrhoea. She denied headache or any visual symptoms. Her past medical history was unremarkable with menarche at age 14 and a previously normal menstrual cycle. She was not taking any regular medications apart from paracetamol and ibuprofen over the counter. She had never used hormonal contraception. On examination, visual fields were full on confrontation and cranial nerves were intact. The thyroid was not palpable, and there were no signs of androgen hormone excess. The remainder of the external examination was unremarkable. She was a cigarette smoker (5/day) and denied alcohol consumption and substance misuse.

\section{Investigation}

Anterior pituitary function assessment revealed markedly elevated serum prolactin at $7081 \mathrm{mIU} / 1$ (reference range 102-496 mIU/l) with negative macroprolactin screen and fully suppressed gonadotropins (luteinising hormone (LH) $<0.1 \mathrm{U} / \mathrm{l}$; follicle-stimulating hormone $(\mathrm{FSH})<0.1 \mathrm{U} / \mathrm{l}$ ). Thyrotrophin (TSH) was $3.3 \mathrm{mIU} / 1$ (3.9-7.7 $\mathrm{mIU} / \mathrm{l})$, free $\mathrm{T}_{4}$ borderline low at $11.5 \mathrm{pmol} / \mathrm{l}(12.0-22.0 \mathrm{pmol} / \mathrm{l}), \mathrm{IGF} 1$ low at $129 \mu \mathrm{g} / \mathrm{l}(270-660 \mu \mathrm{g} / \mathrm{l})$ and adrenocorticotrophin (ACTH) was normal at $21.1 \mathrm{ng} / \mathrm{l}$ (reference range at $0900 \mathrm{~h}$ $<46 \mathrm{ng} / \mathrm{l})$. Serum oestradiol was significantly elevated at $7442 \mathrm{pmol} / \mathrm{l}$ with undetectable $\beta$-human chorionic gonadotropin ( $\beta$-hCG). Serum testosterone was borderline elevated at $2.0 \mathrm{nmol} / 1(0.3-1.7 \mathrm{nmol} / \mathrm{l})$ together with elevated SHBG at $>200 \mathrm{nmol} / 1 \quad(32.4-128 \mathrm{nmol} / \mathrm{l})$. Although prolactin levels $>5000 \mathrm{mU} / \mathrm{l}$ usually indicate the presence of a macroprolactinoma (after exclusion of pregnancy and medication-induced hyperprolactinaemia) (1), MRI of the pituitary with contrast showed an enlarged anterior pituitary with a convex upper border, but no micro or macroadenoma was visible (Fig. 1A).

Given the highly elevated serum oestradiol levels and negative pregnancy test, we considered an ovarian lesion as a source of oestrogens driving lactotroph hyperplasia and prolactin secretion - a state analogous to normal pregnancy. MRI of the abdomen and pelvis showed a $4.8 \mathrm{~cm}$ mass within the right ovary and normal appearances of the uterus and left ovary (Fig. 1B). Serum inhibin B levels were elevated at $2735 \mathrm{ng} / \mathrm{l}$ (reference range $<341 \mathrm{ng} / \mathrm{l}$ in premenopausal women) indicating a presence of a granulosa cell tumour of the ovary (7). Other tumour
A

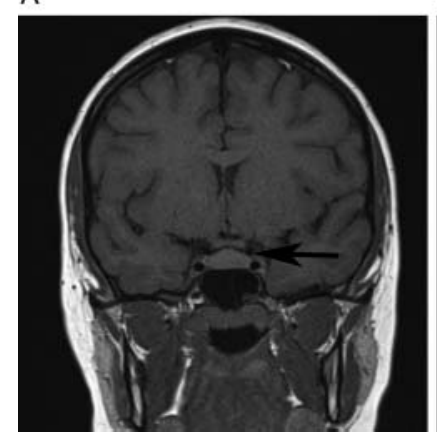

B

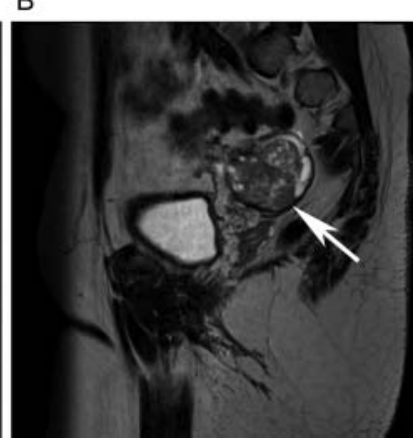

Figure 1

(A) An MRI of the pituitary with contrast, T1-weigthed image, coronal view. The pituitary is enlarged and bulges into the suprasellar cistern (black arrow), but there is no evidence of micro or macroadenoma. (B) MRI of the abdomen with contrast (sagittal view) showed a $4.8 \mathrm{~cm}$ rounded mass within the right ovary (white arrow) and normal appearances of the uterus and left ovary. 
markers including inhibin A (79.7 ng/l; reference range 5-160 ng/l), CA 125 (20 U/ml; reference range 0-30 U/ml) and $\alpha$-fetoprotein $(1.21 \mu \mathrm{g} / \mathrm{l}$; reference range $<8 \mu \mathrm{g} / \mathrm{l})$ were negative.

\section{Treatment}

The patient underwent an uneventful right salpingooophorectomy, and histology confirmed a JGCT of the right ovary which was staged as FIGO 1A (Fig. 2A). Immunohistochemical analysis of the JGCT specimen was negative for prolactin (Fig. 2B).

\section{Outcome and follow-up}

This patient defaulted from endocrine follow-up after surgery. However, she conceived 6 months after the surgery and gave birth to a healthy child. A hormonal profile requested by the patient's general practitioner 2 years after surgery showed a normal oestradiol of $821 \mathrm{pmol} / \mathrm{l}$ and normal prolactin of $327 \mathrm{mIU} / \mathrm{l}$. At the time of writing this report, the patient is pregnant with her second child.
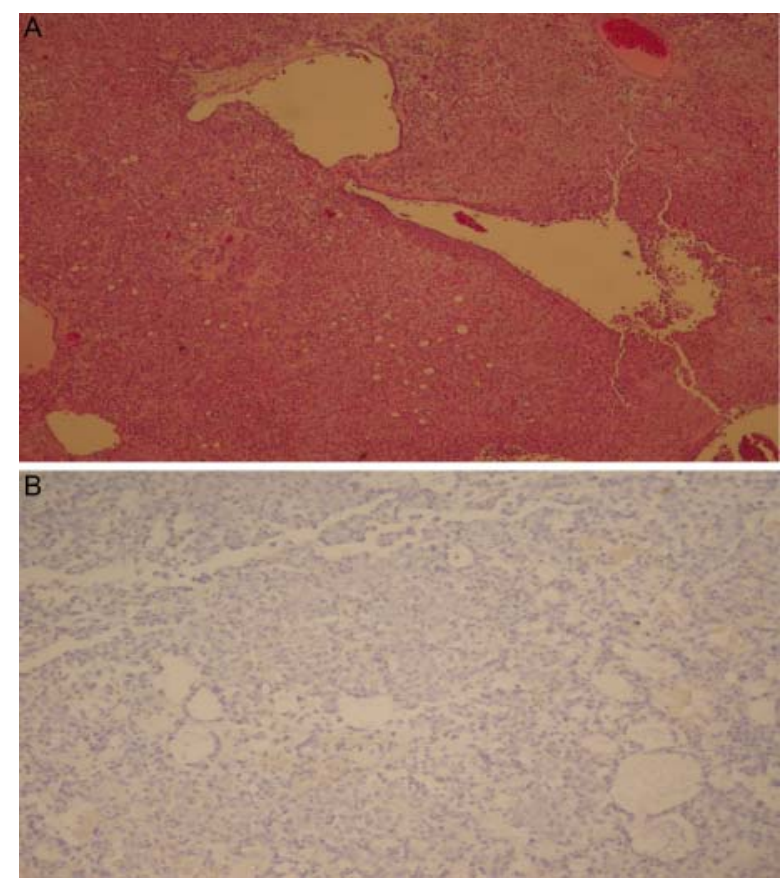

Figure 2

(A) JGCT of the right ovary, FIGO stage 1A. Hematoxylin and eosin staining shows mostly luteinised cells with clear or pale eosinophilic cytoplasm and scattered irregular follicular spaces. (B) Prolactin immunohistochemistry did not identify any significant expression of prolactin within the tumour cells.

\section{Discussion}

We present a case of an oestrogen-secreting JGCT in a 16-year-old woman resulting in hyperprolactinaemia and presenting clinically with galactorrhoea and secondary amenorrhoea. This situation, to an extent, resembles normal pregnancy in which prolactin levels increase approximately tenfold (9) and the pituitary increases in volume more than twofold as a result of oestrogenic stimulation of lactotrophs (10). Surgical removal of the ovarian neoplasm resulted in restoration of fertility as evidenced by the patient's pregnancy 6 months after surgery.

An FSH-producing pituitary adenoma presenting with ovarian hyperstimulation syndrome (OHSS), oligomenorrhoea and bilateral galactorrhoea with elevated FSH, oestradiol and prolactin levels has been previously reported (11). Subsequent transsphenoideal surgery of the pituitary macroadenoma resulted in normalisation of hormonal values and resolution of symptoms. Absence of pituitary lesion on MRI and suppressed FSH levels exclude this clinical scenario in the presented case.

To the best of our knowledge, this is the first report of hyperprolactinaemia as a result of excessive oestrogen production in the context of a JGCT. A Finnish group reported of an aggressive JGCT in a 19-year-old woman secreting prolactin but not oestrogen (5) - a scenario which we managed to exclude by the negative immunohistochemical analysis for prolactin in the JGCT specimen. An Italian group reported a JGCT (FIGO stage 1A) in a 16-year-old woman who presented with secondary amenorrhoea (6). Elevated levels of prolactin (approximately twofold of the upper limit of normal) were detected, but oestradiol levels were normal. The JGCT specimen stained negatively for prolactin, and serum prolactin levels did not normalise following the surgery making it difficult to link the mild hyperprolactinaemia to the presence of the tumour.

JGCTs producing oestradiol, 17-hydroxyprogesterone, DHEA and testosterone were reported in two 16-month old girls presenting with several signs of 'precocious puberty' - transient vaginal bleeding, pubic hair, clitoromegaly and breast enlargement which all regressed following surgical removal of the tumour (3). Several cases of JGCTs producing oestradiol were reported in older age groups (4). Of 33 cases of JGCTs, 14 presented with pseudo-precocious puberty and elevated oestradiol levels. In seven of these patients, oestradiol was also measured after surgery and returned to normal levels in all cases (4). However, prolactin and inhibin levels were not measured in any of these patients. 


\section{Conclusion}

We describe a case of an oestrogen-secreting JGCT with marked hyperprolactinaemia presenting clinically with galactorrhoea and secondary amenorrhoea. Based on immunohistochemistry of the JGCT specimen, we postulate that the observed hyperprolactinaemia was caused by oestrogenic stimulation of pituitary lactotroph cells, a biochemical state analogous to pregnancy. Our case thus illustrates a case of tumour-induced hyperprolactinaemia with a pathophysiology that has not been previously reported in the literature and is currently not reflected in clinical practice guidelines (1).

\section{Declaration of interest}

The authors declare that there is no conflict of interest that could be perceived as prejudicing the impartiality of the research reported.

\section{Funding}

This research did not receive any specific grant from any funding agency in the public, commercial or not-for-profit sector.

\section{Patient consent}

The authors confirm that written informed consent was obtained from the patient for publication of the submitted article and accompanying images through her signature on the consent form.

\section{Author contribution statement}

P Novodvorsky wrote the first draft, did the review of the case and the literature search. A Iqbal, A Lubina-Solomon and J Webster reviewed the patient in the outpatient clinic. Ms F M Kew operated on the patient. All listed authors contributed to the editing process.

\section{Acknowledgements}

We would like to thank $\mathrm{Dr}$ Chris Warren and $\mathrm{Dr}$ Olena Dotsenko, Department of Histopathology, Sheffield Teaching Hospitals NHS
Foundation Trust, Sheffield, UK, for their assistance in acquiring histological images.

\section{References}

1 Melmed S, Casanueva FF, Hoffman AR, Kleinberg DL, Montori VM, Schlechte JA \& Wass JA 2011 Diagnosis and treatment of hyperprolactinemia: an Endocrine Society clinical practice guideline. Journal of Clinical Endocrinology and Metabolism 96 273-288. (doi:10.1210/jc.2010-1692)

2 Schumer ST \& Cannistra SA 2003 Granulosa cell tumor of the ovary. Journal of Clinical Oncology 21 1180-1189. (doi:10.1200/JCO.2003. 10.019)

3 Bouffet E, Basset T, Chetail N, Dijoud F, Mollard P, Brunat-Mentigny M \& David M 1997 Juvenile granulosa cell tumor of the ovary in infants: a clinicopathologic study of three cases and review of the literature. Journal of Pediatric Surgery 32 762-765. (doi:10.1016/S0022-3468 (97)90029-4)

4 Calaminus G, Wessalowski R, Harms D \& Gobel U 1997 Juvenile granulosa cell tumors of the ovary in children and adolescents: results from 33 patients registered in a prospective cooperative study. Gynecologic Oncology 65 447-452. (doi:10.1006/gyno.1997.4695)

5 Santala M, Suvanto-Luukkonen E, Kyllonen A, Ruokonen A \& Puistola U 2001 Hyperprolactinemia complicating juvenile granulosa cell tumor of the ovary. Gynecologic Oncology 82 389-391. (doi:10.1006/gyno.2001.6247)

6 Larizza D, Calcaterra V, Sampaolo P, Lanati G, Brambilla P, Mondello T $\&$ Cesari S 2006 Unusual presentation of juvenile granulosa cell tumor of the ovary. Journal of Endocrinological Investigation 29 653-656. (doi:10.1007/BF03344167)

7 Lappohn RE, Burger HG, Bouma J, Bangah M, Krans M \& de Bruijn HW 1989 Inhibin as a marker for granulosa-cell tumors. New England Journal of Medicine 321 790-793. (doi:10.1056/NEJM198909213211204)

8 Haroon NN, Agarwal G, Pandey R \& Dabadghao P 2013 Juvenile granulosa cell tumor presenting as isosexual precocious puberty: a case report and review of literature. Indian Journal of Endocrinology and Metabolism 17 157-159. (doi:10.4103/2230-8210.107870)

9 Rigg LA, Lein A \& Yen SS 1977 Pattern of increase in circulating prolactin levels during human gestation. American Journal of Obstetrics and Gynecology 129 454-456.

10 Gonzalez JG, Elizondo G, Saldivar D, Nanez H, Todd LE \& Villarreal JZ 1988 Pituitary gland growth during normal pregnancy: an in vivo study using magnetic resonance imaging. American Journal of Medicine $\mathbf{8 5}$ 217-220. (doi:10.1016/S0002-9343(88)80346-2)

11 Cooper O, Geller JL \& Melmed S 2008 Ovarian hyperstimulation syndrome caused by an FSH-secreting pituitary adenoma. Nature Clinical Practice. Endocrinology \& Metabolism 4 234-238. (doi:10.1038/ncpendmet0758)

Received in final form 18 February 2016

Accepted 23 February 2016 